\title{
Comparison of a Latex Agglutination Assay and an Enzyme-Linked Immunosorbent Assay for Detecting Cholera Toxin
}

\author{
ROY J. ALMEIDA, ${ }^{1}$ F. W. HICKMAN-BRENNER, ${ }^{2}$ EVANGELINE G. SOWERS, ${ }^{2}$ NANCY D. PUHR, ${ }^{2}$ \\ J. J. FARMER III, ${ }^{2}$ AND I. K. WACHSMUTH ${ }^{2 *}$ \\ Department of Parasitology and Laboratory Practice, School of Public Health, University of North Carolina, \\ Chapel Hill, North Carolina 27514, ${ }^{1}$ and Enteric Bacteriology Section, Center for Infectious Diseases, \\ Centers for Disease Control, Atlanta, Georgia $30333^{2}$
}

Received 3 July 1989/Accepted 20 September 1989

\begin{abstract}
To determine the pandemic potential of Vibrio cholerae, one must demonstrate both the presence of 01 antigen and the production of enterotoxin (CT). Tissue culture or enzyme-linked immunosorbent assays (ELISAs) for CT have been limited to research and reference laboratories. A kit for detecting CT by reversed passive latex agglutination is now commercially available and was used to test 168 strains of $V$. cholerae 01 and non-01. When compared with the routine ELISA, the latex test was $98 \%$ accurate $(86$ of 88$)$ for serogroup 01 strains and $100 \%$ accurate $(80$ of 80$)$ for non-01 strains. For both 01 and non-O1 study strains, the sensitivity of the latex agglutination test was 0.97 and the specificity was 1.00 when results were compared with ELISA results. The latex test is commercially available and has the advantages of being less complicated and less time-consuming than the ELISA.
\end{abstract}

The outstanding characteristic of Vibrio cholerae is the ability of virulent strains to produce a potent enterotoxin responsible for the watery diarrhea observed in affected patients. $V$. cholerae enterotoxin (CT) was first detected by its ability to cause fluid accumulation in the ligated rabbit ileal loop (5) and later in similarly difficult bioassays such as the infant rabbit infection model (6), rabbit skin test (3), and Y-1 adrenal cell (12) and Chinese hamster ovary cell (7) tissue culture assays. In the 1970s a sandwich enzyme-linked immunosorbent assay (ELISA) for cholera toxin was developed (15) and widely used in many reference and research laboratories. A later modification of the ELISA that used the purified $G_{M 1}$ ganglioside receptor as the capture molecule provided a more standardized approach (14).

Although genetic probe assays for CT have been developed $(2,8)$, their current formats continue to require at least $48 \mathrm{~h}$ and involve the use of radioactive isotopes. Initially, Kaper et al. (8) used a radioactive probe consisting of Escherichia coli heat-labile enterotoxin DNA to demonstrate that enterotoxigenic strains of $V$. cholerae 01 isolated from specimens from Texas and Louisiana carried toxin operon duplications. Klontz et al. (9) used a synthetic oligonucleotide DNA probe for CT to show that $V$. cholerae $\mathrm{O} 1$ strains, with a single toxin gene copy, can also occur on the Gulf Coast of the United States.

Recently, a latex agglutination kit (VET-RPLA; Oxoid U.S.A., Inc., Columbia, Md.) has become commercially available and offers the potential of a rapid, simple diagnostic assay for CT and $E$. coli heat-labile enterotoxin. The purpose of this study was to compare the accuracy, sensitivity, and specificity of the latex agglutination kit with those of a routine ELISA for CT.

A total of 168 strains of $V$. cholerae (88 serogroup 01 strains and 80 non-O1 strains) were used for this study. They were derived from specimens submitted to the Enteric Bacteriology Section of the Centers for Disease Control. All strains were tested for CT by both the ELISA procedure and the latex agglutination kit. Culture materials, conditions, and

\footnotetext{
* Corresponding author.
}

methods were selected on the basis of previous experience with $V$. cholerae $\mathrm{O} 1$ Inaba biotype $\mathrm{El}$ Tor isolates from the U.S. Gulf Coast region. Several studies have shown that optimal culture conditions vary between biotypes and between $\mathrm{O} 1$ and non-O1 serotypes of toxigenic isolates $(4,11$, 13). For example, Craig (4) reported that a stationary culture was more effective than an aerated culture for $V$. cholerae $\mathrm{El}$ Tor isolates but not for classical vibrios in producing CT. The culture medium used in this study for producing $V$. cholerae enterotoxin was a modification of the medium described by Kusama and Craig (10). The medium contained 3\% Casamino Acids, 0.4\% yeast extract (Difco Laboratories), $0.05 \% \mathrm{~K}_{2} \mathrm{HPO}_{4}$, and $0.2 \%$ filter-sterilized glucose ( $\mathrm{pH}$ 7.0). Cultures were grown in 5-ml volumes in screw-cap tubes ( 16 by $125 \mathrm{~mm}$ ) without shaking at $30^{\circ} \mathrm{C}$ for 18 to $24 \mathrm{~h}$. After incubation, tubes were centrifuged at $1,000 \times g$ and $25^{\circ} \mathrm{C}$ for $30 \mathrm{~min}$. One milliliter of supernatant was transferred to a $1.5-\mathrm{ml}$ microcentrifuge tube and centrifuged at $8,000 \times$ $g$ and $4^{\circ} \mathrm{C}$ for $15 \mathrm{~min}$. In order to avoid potential binding of toxin protein to nitrocellulose or any other membrane matrix, filtration was not used. The supernatants of 134 (54 serogroup $\mathrm{O} 1$ strains and 80 non-O1 strains) of the study isolates were assayed simultaneously by latex agglutination and ELISA. The supernatants of 34 serogroup $\mathrm{O} 1$ isolates were assayed only by the latex agglutination test in this study, and results were compared with those from previous ELISAs; if disagreements were noted, the ELISA was repeated.

ELISA. The sandwich ELISA used burro anti-CT adsorbed to round-bottom microdilution wells as the capture molecule. Culture supernatants were added to the coated wells. Cholera toxin molecules in the supernatant bound to the capture antibody and reacted with a second antibody, rabbit anti-CT. Alkaline phosphatase-labeled goat anti-rabbit immunoglobulin was added and acted as the detector molecule. When the enzyme substrate $p$-nitrophenyl phosphate was added, the bound alkaline phosphatase degraded the substrate, forming a yellow product that indicated the presence of CT. Color changes were observed visually and measured by spectrophotometer. A culture was considered 
TABLE 1. Comparison of VET-RPLA and ELISA results in detection of cholera toxin

\begin{tabular}{|c|c|c|c|c|c|c|c|}
\hline \multirow{3}{*}{$\begin{array}{c}V . \\
\text { cholerae } \\
\text { serogroup }\end{array}$} & \multirow{3}{*}{ Region } & \multicolumn{5}{|c|}{ No. of isolates } & \multirow{3}{*}{$\begin{array}{l}\text { No. of } \\
\text { dis- } \\
\text { agree- } \\
\text { ments }\end{array}$} \\
\hline & & \multirow{2}{*}{ Total } & \multicolumn{2}{|c|}{ ELISA } & \multicolumn{2}{|c|}{ VET-RPLA } & \\
\hline & & & Toxin $^{+}$ & $\operatorname{Toxin}^{-}$ & Toxin $^{+}$ & Toxin $^{-}$ & \\
\hline 01 & United States $^{a}$ & 43 & 23 & 20 & 23 & 20 & 0 \\
\hline 01 & Foreign & 45 & 35 & 10 & 33 & 12 & $2^{b}$ \\
\hline Non-O1 & United States & 75 & 3 & 72 & 3 & 72 & 0 \\
\hline Non-O1 & Foreign & 5 & 0 & 5 & 0 & 5 & 0 \\
\hline
\end{tabular}

${ }^{a}$ Continental United States including Alaska.

${ }^{b}$ One isolate was VET-RPLA negative, ELISA positive, Y-1 positive, and probe positive, and one isolate was VET-RPLA negative, ELISA positive, cytotoxic in the $\mathrm{Y}-1$ assay, and probe positive.

positive or toxigenic when the test well had an optical density at least twice that of the negative control wells. Three positive (toxigenic) control strains (569B, E5906, and ATCC 14035) and three negative (nontoxigenic) control strains (X316, 692, and 2634-78) were used on each ELISA plate.

Latex agglutination test. Twofold dilutions of each test sample were made in each of two rows (eight wells per row) of a 96-well microdilution plate. Samples ( $25 \mu \mathrm{l}$ each) were diluted in phosphate-buffered saline containing $0.5 \%$ bovine serum albumin; the last well contained diluent only. Sensitized latex (latex suspension sensitized with specific rabbit immunoglobulin $\mathrm{G}$ against $V$. cholerae enterotoxin; $25 \mu \mathrm{l}$ ) was then added to each well of the first row. An identical amount of control latex (latex suspension coated with nonimmune rabbit globulins) was added to each well of the second row. Microdilution plates were then manually rotated to ensure mixing, covered, and left undisturbed at room temperature for 20 to $24 \mathrm{~h}$, after which each well was examined macroscopically for agglutination. One positive (E5906) and one negative (X316) control strain were included on each latex test plate.

Any discordant results were further examined by the Y-1 adrenal cell assay, which measures toxic activity, and a synthetic oligonucleotide probe (ctxa11) for the CT gene. Additionally, many of the strains in this study had been hybridized with the CT probes as described elsewhere $(2,9)$.

For the $168 \mathrm{~V}$. cholerae strains studied, the latex agglutination test results disagreed with ELISA results in only two instances, when isolates tested positive by ELISA but negative by latex agglutination (i.e., $99 \%$ agreement) (Table 1). For both $\mathrm{O} 1$ and non-O1 study strains, results of the latex agglutination test compared with results of the ELISA gave a sensitivity of 0.97 and a specificity of 1.00 . The accuracy of the latex agglutination test was $98 \%$ ( 86 of 88 ) for serogroup $\mathrm{O} 1$ strains and $100 \%$ (80 of 80 ) for non-O1 strains when results were compared with ELISA results. In every case, ELISA results obtained visually and spectrophotometrically were in agreement. The $88 \mathrm{O} 1$ isolates tested included 43 strains from the continental United States and 45 foreign strains. The 80 non-O1 isolates tested included 75 U.S. strains and 5 foreign strains. The two $\mathrm{O} 1$ isolates that yielded discordant results were both from outside the continental United States (Australia and Mali). Because both ELISA and the latex test are based on antigen-antibody reactions, we tested the two strains that did not agree in the Y-1 adrenal cell assay for toxic activity. The African strain was found to produce CT, as indicated by the apparently more sensitive ELISA. The strain from Australia was cytotoxic in the Y-1 adrenal cell assay. This cytotoxicity was not neutralizable by rabbit anti-cholera toxin. The two $\mathrm{O} 1$ isolates both tested positive for the CT gene after overnight hybridization with the probe for CT. No disagreements were found between the ELISA and latex agglutination test results for the 118 U.S. isolates, including strain $2489-86$, which had been shown to differ from other U.S. isolates in having only one apparent copy of the CT gene (9). The fact that both disagreements involved foreign isolates could indicate that the growth conditions used in this study were not optimal for CT production by strains from geographic areas other than the United States. Kaper et al. (8) reported that most El Tor strains isolated from outside the United States had only a single CT gene copy. Our positive control strain E5906 was isolated in Dacca, Bangladesh, and was a low-level toxin producer in the quantitative $\mathrm{Y}-1$ assay. In contrast, all toxigenic Gulf Coast strains, with the exception of strain 2489-86, possess toxin operon duplications.

The serogroup $\mathrm{O} 1$ characteristic has been the primary marker for pandemic, pathogenic $V$. cholerae strains. It is becoming apparent, however, that not all $V$. cholerae $\mathrm{O} 1$ strains are toxigenic and they may not be pathogenic. Strains of nontoxigenic $V$. cholerae $\mathrm{O} 1$ have been isolated from humans, sewage, oysters, and surface water (1). Most clinical laboratories do not test for the ability of isolates to produce CT because the laboratories lack tissue culture facilities and CT-ELISA reagents are not readily available. Instead, suspect isolates are sent to reference laboratories for toxin testing. This situation results in considerable delay in identifying toxigenic $V$. cholerae isolates that must be reported immediately to the World Health Organization. If clinical laboratories could quickly determine the toxigenicity of $V$. cholerae $\mathrm{O} 1$ isolates, the international surveillance and possible epidemiologic investigation of cholera would be significantly facilitated.

On the basis of findings from this study, we recommend the use of the Oxoid latex agglutination kit in clinical as well as reference laboratories. The kit is designed to detect 1 to 2 $\mathrm{ng}$ of cholera toxin per $\mathrm{ml}$ and is relatively convenient to use. Frequently, laboratories receive requests for CT determinations on single specimens. Since the ELISA uses microdilution plates with precoated wells, it is not an efficient method for assaying small numbers of specimens. The design of the latex agglutination test, on the other hand, allows for the dispensing of requisite amounts of antigens and antibodies into uncoated microdilution wells. The kit provides diluent and latex reagents that are ready for use. Therefore, the format of the latex agglutination test is more appropriate for the rapid detection of $\mathrm{CT}$ in situations involving small numbers of specimens. Minimal time and effort are needed for setup and interpretation of results. The latex test is commercially available and is simpler and faster than the CT-ELISA. Thus, the VET-RPLA kit is well suited for use in field studies and by most clinical microbiology laboratories.

Although no false-negative results occurred with the U.S. isolates when the latex agglutination test was used in this study, an overall $3.4 \%$ false-negative rate was noted. Since a false-negative reaction is possible and the isolation of $V$. cholerae $\mathrm{O} 1$ in the United States is considered to be relatively rare, clinical laboratories should forward $V$. cholerae $\mathrm{O} 1$ specimens, regardless of toxin assay result, to a reference laboratory for confirmation of identification, serotype, and toxin (by ELISA, Y-1 adrenal cell assay, or DNA probe). 


\section{LITERATURE CITED}

1. Blake, P. A. 1981. New information on the epidemiology of Vibrio infections, p. 107-117. In T. Holme, J. Holmgren, M. H. Merson, and R. Mollby (ed.), Acute enteric infections in children: new prospects for treatment and prevention. Elsevier/ North-Holland Biomedical Press, New York.

2. Cook, W. L., K. Wachsmuth, S. R. Johnson, K. A. Birkness, and A. R. Samadi. 1984. Persistence of plasmids, cholera toxin genes, and prophage DNA in classical Vibrio cholerae 01. Infect. Immun. 45:222-226.

3. Craig, J. P. 1965. A permeability factor (toxin) found in cholera stools and culture filtrates and its neutralization by convalescent cholera sera. Nature (London) 207:614-616.

4. Craig, J. P. 1985. The vibrio diseases in 1982: an overview, p. 11-23. In Y. Takeda and T. Miwatani (ed.), Bacterial diarrheal diseases. KTK Scientific Publishers, Tokyo.

5. De, S. N., and D. N. Chatterje. 1953. An experimental study of the mechanism of action of Vibrio cholerae on the intestinal mucous membrane. J. Pathol. Bacteriol. 66:559-562.

6. Dutta, N. K., and M. K. Habbu. 1955. Experimental cholera in infant rabbits: a method for chemotherapeutic investigation. $\mathrm{Br}$. J. Pharmacol. Chemother. 10:153-159.

7. Guerrant, R. L., L. L. Brunton, T. C. Schnaitman, L. I. Rebhun, and A. G. Gilman. 1974. Cyclic adenosine monophosphate and alteration of Chinese hamster ovary cell morphology: a rapid, sensitive in vitro assay for the enterotoxins of Vibrio cholerae and Escherichia coli. Infect. Immun. 10:320-327.

8. Kaper, J. B., H. B. Bradford, N. C. Roberts, and S. Falkow.
1982. Molecular epidemiology of Vibrio cholerae in the U.S. Gulf Coast. J. Clin. Microbiol. 16:129-134.

9. Klontz, K. C., R. V. Tauxe, W. L. Cook, W. H. Riley, and I. K. Wachsmuth. 1987. Cholera after the consumption of raw oysters. Ann. Intern. Med. 107:846-848.

10. Kusama, H., and J. P. Craig. 1970. Production of biologically active substances by two strains of Vibrio cholerae. Infect. Immun. 1:80-87.

11. Richardson, S. H. 1969. Factors influencing in vitro skin permeability factor production by Vibrio cholerae. J. Bacteriol. 100: 27-34.

12. Sack, D. A., and R. B. Sack. 1975. Test for enterotoxigenic Escherichia coli using Y1 adrenal cells in miniculture. Infect. Immun. 11:334-336.

13. Spira, W. M., and P. J. Fedorka-Cray. 1983. Production of cholera toxin-like toxin by Vibrio mimicus and non-O1 Vibrio cholerae: batch culture conditions for optimum yields and isolation of hypertoxigenic lincomycin-resistant mutants. Infect. Immun. 42:501-509.

14. Svennerholm, A.-M., and J. Holmgren. 1978. Identification of Escherichia coli heat-labile enterotoxin by means of a ganglioside immunosorbent assay $\left(\mathrm{G}_{\mathrm{m} 1}\right.$-ELISA) procedure. Curr. Microbiol. 1:19-23.

15. Yolken, R. H., H. B. Greenberg, M. H. Merson, R. B. Sack, and A. Z. Kapikian. 1977. Enzyme-linked immunosorbent assay for detection of Escherichia coli heat-labile enterotoxin. J. Clin. Microbiol. 6:439-444. 